\title{
Improving Roadway Navigation and Safety of Older Age Drivers
}

\author{
Mohammed Said Obeidat ${ }^{1}$ \\ ${ }^{1}$ Department of Industrial Engineering, College of Engineering, Jordan University of Science and Technology, Jordan \\ Correspondence: Mohammed Said Obeidat, Industrial Engineering Department, Jordan University of Science and \\ Technology, Irbid 22110, Jordan. E-mail: msobeidat1@ @ust.edu.jo
}

Received: March 19, 2018 Accepted: April 4, 2018 Online Published: May 2, 2018

doi:10.5539/res.v10n2p150

URL: https://doi.org/10.5539/res.v10n2p150

\begin{abstract}
Motor vehicles are the primary mode of transportation worldwide, but drivers must simultaneously utilize various skills and perform multiple tasks at the same time to safely operate the vehicle. As people age, however, physical changes can affect daily life, possibly contributing to declining driving skills. These changes affect vision, hearing, reaction time, and cognitive and motor ability, thus complicating driving. This paper discusses the importance of driving for people of age 65 and older, age-related physical changes, and methods of improving overhead guide sign visibility on roadways. Suggestions to improve navigation and safety on roadways, especially for older people, are presented, including the use of autonomous vehicles fleet.
\end{abstract}

Keywords: Safety, Older Driver, Driving, Autonomous Vehicle

\section{Introduction}

Motor vehicles are essential modes of transportation worldwide for drivers of all ages. To safely operate a motor vehicle, however, drivers must simultaneously utilize various skills and perform multiple tasks while accounting for factors such as other roadway users, traffic signals, signs, and environment (Dukic \& Broberg, 2012). Based on road statistics, the most important driving skills include the acquisition and processing of information and the ability to make appropriate decisions when needed (Dewar \& Olson, 2007).

Despite the age of drivers, more driving difficulties are faced during nighttime driving. Several driver's issues may affect roadway visibility such as driver's contrast sensitivity, visual acuity, judgment on distances, and discrimination of colors (Lagergren, 1987). In the U.S., green signs located along roads are called guide signs. These signs are essential for boosting driver's guidance and safety by providing guidance and information regarding destinations (Obeidat M. S., Rys, Russell, \& Gund, 2014a).

Currently, the elderly population, age 65 and older, in the U.S. has increased dramatically. Population projections report that the number of U.S. seniors, ages 65 and older, is expected to more than double between 2012 and 2060, from 43.1 million to 92 million (U.S. Census Bureau, 2012). In 2060, the older population will represent more than one in five U.S. residents compared to one in seven in 2012 (U.S. Census Bureau, 2012). In addition, the increase in the "oldest old" number will be even greater: residents 85 years and older are projected to more than triple, from 5.9 million to 18.2 million, reaching $4.3 \%$ of the total population in the same time interval (U.S. Census Bureau, 2012).

An important focus of the Federal Highway Administration (FHWA) in the U.S. is to increase road safety. Based on the National Highway Traffic Safety Administration's (NHTSA) Fatality Analysis Reporting System (FARS), 37,461 people were killed in motor vehicle traffic crashes in the U.S. in 2016 (National Highway Traffic Safety Administration [NHTSA], 2017). Despite the fact that $25 \%$ of all vehicle travel occurs during night, about $50 \%$ of traffic fatalities occur during night (Federal Highway Administration [FHWA], 2008), (Obeidat \& Rys, 2017).

As required by the Manual on Uniform Traffic Control Devices for Streets and Highways (MUTCD), overhead roadway guide signs should be manufactured from retroreflective sheeting materials or illuminated (FHWA, 2009). Departments of Transportation (DOTs) in the U.S. are considering two options: adding light sources to the currently installed overhead guide signs on roadways or replacing old signs by new retroreflective sheeting material to increase sign visibility to drivers, especially old age drivers, at night to decrease the potential crashes possibility, which resulted from driver confusion and improper maneuvers.

This paper discusses the importance of driving for older people and corresponding age-related physical changes. Suggestions to improve navigation and safety on roadways, especially for older drivers, are presented for DOTs and transportation agencies, including the use of autonomous vehicle fleets. 


\section{Literature Review}

\subsection{Importance of Driving for Older Populations}

For an independent, active elderly person, maintaining mobility outside the home is essential (Born, et al., 2010). A private vehicle connects seniors to services, goods, and other activities for which they must have a high level of independence. Motor vehicles are the main transportation media among senior people in the U.S. (Foley, Heimovitz, Guralnik, \& Brock, 2002). This travelling trend is becoming increasingly popular in Europe, as well (Talbot, et al., 2005). The most reliable and convenient media of transportation is driving, especially in areas with little or no public transportation (Born, et al., 2010). In addition, driving can provide physical and social benefits of personal transportation and mobility for seniors. Conversely, loss of personal mobility, especially for seniors, may lead to depression and physical and mental illnesses (Phillips, Rousseau, \& Schwartzberg, 2006). Driving cessation can also lead to negative economic and psychosocial consequences (Born, et al., 2010). For example, the loss of driving privileges can cause difficulty for former drivers to obtain required services and goods, such as, doctor's appointments, groceries, and their frequency of social opportunities with friends and relatives may be reduced (Born, et al., 2010).

People over 65 years of age utilize private vehicles, either as drivers or passengers, for approximately $90 \%$ of their daily errands (Houser, 2005). Approximately $44 \%$ of these errands are for shopping, $27 \%$ are for meals, social activities, and recreation, $13 \%$ are for school, religious issues, and family, $5 \%$ are for medical issues, $4 \%$ are related to work, and $7 \%$ are as passengers (Houser, 2005).

\subsection{Age-Related Driving Issues}

As people age, physical changes occur which can affect daily life, including functions that may reduce driving skills. These changes affect vision, hearing, reaction time, and cognitive and motor ability, thus complicating driving or walking (Houser, 2005). While many senior drivers are able to compensate for declined functions with experience and safe driving habits, aging uniquely affects each individual (Houser, 2005).

Studies related to senior drivers have shown that crash rates associated with increasing age are most likely related to declining driving abilities and medical conditions that can affect and impair driving (Bayam, Liebowitz, \& Agresti, 2005). According to (Zhang, Lindsay, Clarke, Robbins, \& Mao, 2000), although physical health and medical conditions did not predict fatality risk for drivers aged 65 to 74 , medical conditions, such as diabetes mellitus, epilepsy, and chronic heart disease, were found to significantly increase fatality risks for drivers over the age of 75 .

The act of driving presents many challenges for drivers of all ages. At night, signs and roadway markings are difficult to see and small lettering on roadway signs may be difficult to read even during the day. Large roadway intersections with multiple lanes and access roads can be complicated and confusing for any driver, especially for older drivers (Houser, 2005). In addition, seniors typically prefer to drive older vehicles, most of which lack advanced safety features found in modern vehicles. As a result, driver safety is reduced (Houser, 2005). The following sections provide details regarding age-related driving issues.

\subsubsection{Visual Acuity}

Declining vision can significantly affect seniors' driving, causing difficulty in seeing roadway signs, traffic signals, pavement markings, and pedestrians or passing animals. Nighttime driving is especially challenging because of interference of low-level lighting and glare from other vehicle headlights with a driver's vision (FHWA, 2003). Vision changes for older drivers often affect the distance at which they can detect traffic signs and recognize sign lettering. These changes may also affect the ability to see and detect pavement markings (Amparano \& Morena, 2006). Because of these visual deficiencies, senior drivers are often hesitant to make decisions regarding lane changes or exiting, thus affecting their safety and the safety of other roadway users.

Contrast sensitivity is defined as "the ability to discern brightness differences between adjacent areas" (Phillips, Rousseau, \& Schwartzberg, 2006). Declining contrast sensitivity prevents older drivers from noticing faded pavement markings during nighttime driving. Visual declines are a prominent cause of driving problems for seniors. Elderly drivers often feel a decline in their capability to clearly distinguish stimuli under various driving conditions, and many seniors experience visual field narrowing (Bayam, Liebowitz, \& Agresti, 2005). In addition, senior drivers commonly fail to notice objects in motion (Bayam, Liebowitz, \& Agresti, 2005).

According to Phillips et al. (2006), the function of the lens in the human eye is to focus light onto the retina. Two key changes occur to an eye lens with age: flexibility reduction and yellowing. Flexibility reduction causes difficulty in shifting focus from near objects to objects farther away. In fact, Presbyopia, or nearsightedness, is a vision deficiency in which the crystalline lens of the eye loses its flexibility, making it complicated for the person to focus on close objects (American Optometric Association, 2006). Eye lens yellowing causes older adults to require more light to detect objects clearly. Although seniors' eyes benefit from additional light, they are sensitive to glare. Glare "stems from excessive 
contrast between bright and dark areas in the field of view" and is a serious concern for roadway safety because it may limit adjustments to brightness differences at nighttime for pedestrians and drivers (Avrenli, Benekohal, \& Medina, 2012). Another change that occurs as a result of increasing age is declining peripheral vision (Phillips, Rousseau, \& Schwartzberg, 2006).

Visual acuity is defined as "the ability to resolve detail" (Owsley \& McGwin, 2010). The World Health Organization classifies different categories of visual disability, including low vision and blindness. Low vision is defined as "visual acuity between 20/60 and 20/200 or corresponding visual field loss to less than 20 degrees in the better eye with best possible correction" (Steinkuller, 2010). Blindness is defined as "visual acuity of less than 20/400 or corresponding visual field loss to less than 10 degrees in the better eye with the best possible correction" (Steinkuller, 2010).

Visual acuity screenings performed for first-time driver's license applicants and drivers' periodically seeking re-licensure is reasonable. In the U.S., roadway sign design is based on sight distances which assume that binocular visual acuity for drivers is at least 20/30 (FHWA, 2009). Drivers with less visual acuity experience difficulty in reading directional road signs at safe distances in order to make common driving decisions such as changing lanes or exiting (Owsley \& McGwin, 2010).

Visual acuity test in the U.S. is almost the same among all states. For unrestricted licensed drivers, states have similar visual acuity requirements for licensure (either first time or re-license), and most states have determined the minimum best-corrected visual acuity (BCVA) requirement at 20/40. European Union have established a standard that dominates the minimum visual acuity requirements for driving license in Europe (Born, et al., 2010). Vehicle and motorcycle drivers in Europe must have binocular visual acuity of at least 20/40 with or without correction, and standards of binocular visual field are specified no less than $120^{\circ}$ (Born, et al., 2010). In the U.S., some states have shortened the period of driving license validity for certain ages for one or two years in order to test the driver vision. For example, Connecticut and Pennsylvania have a two years option of driving license for people of 65 years, Hawaii issues a two years driving license for people of 72 years and over, Rhode Island issues a two years driving license for people of 75 years and over, Illinois permit two years driving license for ages between 85-86 years and one year for age 87 years and over, and Texas issues a two years driving license for people 85 years and over (Highway Safety Research and Communications, 2018).

\subsubsection{Increasing Reaction Time}

Another problem faced by senior drivers is a decline in reaction time, defined by the response speed of a person to an event (Green, 2000). Reaction time is a measure of the processing speed of the central nervous system of the body (Der $\&$ Deary, 2006), (Madden, 2001). According to Der and Deary (2006), reaction time is strongly associated with age; as age increases, reaction time increases. Older drivers typically respond more slowly to traffic control devices and changes in traffic or roadway conditions, such as a motor vehicle accident or a detour.

Reaction time consists of several components according to occurrence sequence. The first component is mental processing time, defined as "the time it takes for the responder to perceive that a signal has occurred and to decide on a response" (Green, 2000). For example, mental processing time is the time spent by a driver to detect that the traffic signal directly ahead has become yellow and decide that the brake should be applied. This segment of time is referred to as perception reaction time (Warshawsky-Livne \& Shinar, 2002). The second component of reaction time is movement time: This requires the performance of certain muscle movements after determining an appropriate response (Green, 2000). For example, movement time includes the time required to lift the foot off the accelerator pedal, move it to the brake pedal, and then depress the brake pedal. In general, movement time increases with more complex movements (Green, 2000). The third component of reaction time is device response time. After the responder acts, the mechanical devices require certain time to engage (Green, 2000). For example, when the driver depresses the brake pedal, the car does not stop immediately because the stopping is controlled by gravity and friction (Green, 2000). Time is required for the devices within the car to overcome those forces and stop the vehicle.

\subsubsection{Physical Limitations}

Physical changes to senior drivers often contribute to difficulty in head movements to scan right and left sides at intersections or interchanges or look over their shoulders for lane changes (FHWA, 2003). McKnight stated that senior drivers often experience difficulty when backing up because elderly drivers encounter physical limitations in upper body and head motion related to backward driving (McKnight, 2003).

A primary reasons why old age drivers make accidents during lane changes and left turns is because of the physical limitations in their upper body motion including neck and back pain, which make looking behind before reversing extremely difficult, or they may fail to carefully check vehicle blind spots before changing lanes (Bayam, Liebowitz, \& Agresti, 2005).

A decline in hearing is another physical limitation due to increased age. Hearing is essential for safe driving because it 
allows drivers to react properly to emergency vehicles such as ambulances or police sirens. Hearing also allows drivers to respond to honking horns of other drivers when warning of dangers or mistakes. As a result, seniors' hearing decline reduces driver safety.

\subsubsection{Cognitive Functions}

Cognitive ability is "the ability to acquire, store, and apply knowledge, including short-term and long-term memory as well as performing mental operations" (Bayam, Liebowitz, \& Agresti, 2005). Older drivers often have difficulty cognitively sorting the huge amount of roadway information incurred while driving. This difficulty is especially dangerous when encountering critical zones on roadways, such as navigating a temporary traffic control zone because of a detour (FHWA, 2003). Cognitive ability declines as age increases (Bayam, Liebowitz, \& Agresti, 2005), and cognitive functions and visual attention measures have been shown to be accurate accident frequency predictors for senior drivers (Daigneault, Joly, \& Frigon, 2002).

The ability of senior drivers to share attention while driving also declines with age. Certain driving situations can be especially challenging, such as making left turns at intersections in which drivers must split their attention between oncoming traffic and pedestrian traffic on either side of the vehicle (Bayam, Liebowitz, \& Agresti, 2005). Other situations requiring shared attention involve interaction with traffic control devices such as red light traffic signals or stop signs (Bayam, Liebowitz, \& Agresti, 2005).

In addition to senior drivers' deficiency in attention-sharing, impaired judgment regarding traffic gaps may result into indecisive passing traffic at intersections (Bayam, Liebowitz, \& Agresti, 2005). Senior drivers often have difficulty judging the location of approaching traffic relative to their ability to accelerate into gaps (McKnight, 2003). Older drivers often resolve the conflict created by their inability to handle the situation they faced while driving by slowing down or stopping, which can cause additional dangers (Bayam, Liebowitz, \& Agresti, 2005). Most traffic accidents occur when senior drivers operate their vehicles at a slower speed than the flow of traffic (Bayam, Liebowitz, \& Agresti, 2005).

\subsection{Visibility Improvement Methods for Overhead Guide Signs}

Guide signs should be clear and visible to drivers to allow a proper response time. High visibility and legibility are essential attributes for guide signs. Legibility is defined as "the readability of a particular writing style, or font" (Amparano \& Morena, 2006). Many required standards regarding signs are mentioned and explained in the MUTCD. The visibility of overhead guide sign could be increased either by using retroreflective sheeting materials or adding light sources to illuminate the sign.

\subsubsection{Retroreflective Sheeting Materials}

The American Society for Testing and Materials (ASTM) specifies the requirements of sheeting materials used in manufacturing retroreflective guide signs. ASTM D4956-11a standard describes types of retroreflective sheeting materials that can be used on traffic signs, including eleven types of retroreflective sheeting and their various applications (ASTM, 2011). These eleven types are categorized into three categories of sign sheeting: Engineering Grade, Diamond Grade, and High Intensity.

Retroreflective sheeting materials are commonly used on U.S. highways by some DOTs (Bullough, Skinner, \& O'Rourke, 2008). According to national surveys, the most used retroreflective sheeting material for overhead guide sign legends in the U.S. is Diamond Grade (type IX, followed by type XI), and High Intensity (types III and IV) is the most common retroreflective sheeting material used for guide sign backgrounds (Obeidat, Rys, Russell, \& Gund, 2014a). An important advantage of retroreflective sheeting is that they do not rely on electrical power, their concept is based on retroreflection in which illuminance from oncoming vehicle headlamps reflected back toward the vehicle.

The use of retroreflective sheeting materials makes the signs more visible, especially in high visual "noise" areas (Amparano \& Morena, 2006). Results of a project conducted at the University of South Dakota showed that the required time by older age drivers to detect signs in complex backgrounds can be decreased excessively by using super-high-intensity sheeting material (Amparano \& Morena, 2006).

A field experiment was conducted to evaluate guide signs manufactured from three retroreflective sheeting materials (Obeidat, Rys, \& Rys, 2014b), (Obeidat, Rys, Rys, \& Du, 2016). The researchers studied Engineering Grade (type III), High Intensity (type IV), and Diamond Grade (type XI) retroreflective sheeting. They found that Diamond Grade (type XI) provides the highest visibility for drivers. Researchers also performed cost analysis for the three retroreflective sheeting materials. Their study concluded after merging decision criteria of sign visibility and cost of retroreflective sheeting, that High Intensity (type IV) retroreflective sheeting to be used by DOTs in order to improve guide sign visibility (Obeidat, Rys, Rys, \& Du, 2016). 


\subsubsection{Illumination}

Roadway lighting is a public amenity that participates in providing a safer environment for roadway users. Safety, security and traffic flow operations could be increases by efficient road lighting (Medina, Avrenli, \& Benekohal, 2013). Roadway conditions and geometry are easily recognized when a proper roadway lighting is existed.

A light source is a device that converts electrical power into visible light. Light sources associated with little short-wavelength light are less effective for vision than light sources that produce greater short-wavelength (blue), even if the measured light level is similar, because of the human eye's shifted response to light at some nighttime light levels, this is true for certain locations in the field of view and for certain light levels (Bullough, 2012a). Wavelength is defined as the distance between two consecutive points of the same wave. Light sources used for road lighting purposes include incandescent lamps, electric discharge lamps, induction lighting and Light Emitting Diode (LED).

In incandescent lamps, an electric current passes through a wire, causing it to heat to a certain level which allows the wire to glow and emit light (Lopez, 2003). Two types of incandescent lamps are available: common incandescent and tungsten halogen (Lopez, 2003). Both types are low in cost but have low efficacy (lumen per watt).

Electric discharge light sources produce light through by passing an electric current through a gas or vapour (Lopez, 2003). Five types of electric discharge light sources are commonly used: Fluorescent, Induction Fluorescent, Mercury Vapor (MV), High Pressure Sodium (HPS), Low Pressure Sodium (LPS), and Metal Halide (MH) (Lopez, 2003). For MV light sources, phosphor-coated and clear light are exists. MV light sources also contain a phosphor-coated light source used primarily in sign lighting applications (Lopez, 2003). Light is produced in HPS light sources by an arc in a ceramic tube that contains sodium and additional elements (Lopez, 2003). Light in LPS light sources is produced by an arc in a long tubular glass bulb that contains sodium only (Lopez, 2003). The MH light source is similar to the mercury light source, but, in addition to mercury, $\mathrm{MH}$ contains various metal halides which provide excellent color rendering resulting in a white light (Lopez, 2003). Induction lighting is a modern fluorescent lamp that relies on radio frequencies to stimulate lamp material to produce light, (Bullough, 2012b). LEDs are "semiconductors that emit light when electrical current runs through them" (Avrenli, Benekohal, \& Medina, 2012).

Obeidat and Rys (2015) studied five light sources that are used for illuminating overhead guide sign. The studied light sources were the 62 watt LED, the 85 watt induction, the 250 watt MH, the 250 watt HPS, and the 250 watt MV. Several criteria were considered in comparison including light distribution of each light source, annual cost, and if the light source can be legally used in U.S. They recommended using the 85 watt induction light source to DOTs.

\section{Solutions for Improving Roads to Enhance Population's Safety}

Navigating U.S. roadways is somehow confusing and challenging for drivers of different ages when driving routes are not clearly understood or easily marked, especially when the driver is unfamiliar with the area (Amparano \& Morena, 2006). This problem is extremely enormous for senior drivers, especially those who have physical and cognitive disabilities (Amparano \& Morena, 2006). However, engineering opportunities such as retroreflectivity, sign placement, legibility of sign lettering and sign size can improve a driver's capability to detect signs and comprehend their messages. Solutions for improving roadway navigation and increasing safety are discussed in the following sections.

\subsection{Reducing the Impact of Vision Decline}

Based on research conducted by Phillips, Rousseau and Schwartzberg (2006), a number of infrastructure measures could be utilized to decrease the impacts of vision decline for senior drivers (Phillips, Rousseau, \& Schwartzberg, 2006). One direct step is to increase the size of roadway signs and lettering. If drivers are able to read sign information from a greater distance, they will have enough time to make navigation decisions, thus enabling increased focus on safe maneuvers. The Manual on Uniform Traffic control Devices (MUTCD) recommends minimum sign and font sizes for various types of signs: minimum upper case letter size is 8 in $(200 \mathrm{~mm}$ ) and lower case letter size is 6 in (or $150 \mathrm{~mm}$ ). These sizes are used for multi-lane streets with speed limits greater than $40 \mathrm{mph}$ (or $65 \mathrm{~km} / \mathrm{hour}$ ) (FHWA, 2009). To enhance guide sign visibility for nighttime driving, a light source may be installed or guide sign sheet metal material can be replaced by a bright retroreflective material which has the effect of enhancing sign visibility at night.

Several font types including Series A (discontinued), Series B, Series C, Series D, Series E, Series E (Modified), Series F, and ClearviewHwy ${ }^{\mathrm{TM}}$ font can be used on signs. ClearviewHwy ${ }^{\mathrm{TM}}$ font (hereafter referred to as Clearview) was developed by Donald Meeker and Christopher O'hara of Meeker and Associates, Inc.; Martin Pietrucha, Ph.D., and Philip Garvey of the Pennsylvania Transportation Institute; and James Montalbano of Terminal Design, Inc., along with research supported by Paul Carlson, Ph.D., and Gene Hawkins, Ph.D., and research design advice by Susan Chrysler, Ph.D., of the Texas Transportation Institute (Holick, Chrysler, Park, \& Carlson, 2006). Recent studies on guide signs have shown that Clearview's alphabet legibility facilitates a $16 \%$ improvement in distance recognition by senior drivers and a $12 \%$ increase in legibility for all drivers when compared to the series E (modified) font (Amparano \& Morena, 2006). 
Clearview font results in faster reading, comprehension, recognition and reaction times for drivers, especially older age drivers. Many states have used Clearview font as a part of their transportation system such as Arizona, Iowa, Kentucky, Maryland, Michigan, Pennsylvania, Texas, and Virginia.

Roadway curves represent another major visual challenge. A majority of fatal crashes occur on U.S. rural roadways, and a wide portion of these crashes occur on horizontal curves (Momeni, Russell, \& Rys, 2015). Older drivers have difficulty detecting sharp curves, especially during nighttime driving. However, many countermeasures can increase safety on curves. These countermeasures vary from low to high cost. Examples of low cost countermeasures include centerline, edge line, horizontal alignment signs, advisory speed signs, chevrons and one-direction large arrow sign, combination of horizontal alignment and advisory speed sign, curve speed sign, alignment sign, delineators, profile thermoplastic and raised pavement marking, reflective barrier delineation, speed limit advisory marking, optical speed bar, and rumble strips of all types (Momeni, Russell, \& Rys, 2015). Other medium and high cost countermeasures include flashing beacons, dynamic curve warning system, paved and widening shoulders, shoulder drop-off elimination, installation or lighting improvement, and skid resistance pavement surface (Momeni, Russell, \& Rys, 2015). Several studies were performed on these countermeasures to show the benefits of each for safety improvement on curves. All these techniques increase detection of roadways and improve safety, which is beneficial to all drivers, including older drivers.

\subsection{Improving Roadway Navigation}

The use of redundant street name signs could increase the chances of a driver remembering critical navigation information (Phillips, Rousseau, \& Schwartzberg, 2006). Often, when drivers see a road sign, they are quickly distracted and forget the required intersection (Phillips, Rousseau, \& Schwartzberg, 2006). This distraction initially deletes necessary navigation information from working memory (Phillips, Rousseau, \& Schwartzberg, 2006). Because working memory capacity declines with age, these memory lapses are more common for older drivers. Providing roadway navigation information several times to a driver (using redundant street name signs) helps limit this issue.

Seniors commonly prefer driving on familiar roadways (Phillips, Rousseau, \& Schwartzberg, 2006). Unfortunately, even familiar areas often change, as in work zones or required detours. Changeable message signs are an important method for transportation agencies to alert drivers to new road situations. However, appropriate design of these signs is crucial so that drivers of all ages can easily navigate roadways.

One smart-modern solution to improve safety for older people on roadways is to implement autonomous vehicles' "self-driving cars" service. Google has begun building a fleet of electric power vehicles to be used for experimentation in California (Markoff, 2014). According to Markoff (2014), these vehicles were based on a principle of completely removing driver responsibility from the vehicle; no steering wheel, gas pedal, brake pedal, or gear shift is necessary. The only element available in the vehicle is a red "e-stop" button that can be used by the passenger in emergency stops and a separate start button. These vehicles are requested via a smart phone application. The speed limit of these vehicles is limited to $25 \mathrm{mph}$, though, these vehicles are designed for urban and suburban areas, not on highways. One potential use for these vehicles is driverless taxi cabs.

Based on Markoff (2014), Google's autonomous vehicle had sensors that can detect approximately $600 \mathrm{ft}$ in all directions. This vehicle had a rear view mirror according to California code. A foam-like material will be used in the construction of the front of the vehicle in case the vehicle's computer fails and the vehicle hits a pedestrian. Google's vehicle differs from vehicles introduced by Mercedes, BMW, and Volvo because those vehicles were able to travel within limited circumstances without a driver but they did not completely eliminate the driver as in Google's vehicle.

Comparing to the other modes of transportation, autonomous vehicles are better in terms of time, safety, convenience, and peace of mind (Burns, Jordan, \& Scarborough, 2013). Based on Burns, Jordan and Scarborough (2013), initial estimates of the new autonomous vehicles are $\$ 4$ per customer per day, or \$2 per customer per trip (Burns, Jordan, \& Scarborough, 2013). The fleet system of autonomous vehicles can be an alternative transportation media, competing with taxicabs and public transportation. Yellow taxicab fare in Manhattan, New York is approximately $\$ 5$ per mile, while initial estimates of the fleet fare of a shared, driverless vehicle are approximately $\$ 0.50$ per mile. In addition, the autonomous shared, driverless vehicle service is more convenient and less expensive than the bus or subway, resulting in the reduction of empty miles and labor costs and increased energy efficiency. 


\section{Conclusions}

Motor vehicles are an efficient method of transportation for a majority of people. As people age, physical changes occur which can affect their daily life, including functions that may cause driving skills to decline. These changes affect vision, hearing, reaction time, and cognitive and motor ability and may complicate driving.

Improving roadway safety can be accomplished through various methods such as: Using brighter retroreflective sheeting materials, illumination signs, and using the autonomous vehicle fleet. The future of autonomous vehicles fleet is considered a modern and a smart solution to increase safety on roadways, especially for older drivers. These vehicles appear to be more efficient than other transportation methods such as private vehicles, taxicabs, and public transportation in terms of cost, time, and energy saving.

\section{References}

American Optometric Association. (2006). Presbyopia. Retrieved January 18, 2018, from http://www.aoa.org/x4697.xml

Amparano, G., \& Morena, D. (2006). Senior mobility series: Article 4-marking the way to greater safety. Washington, DC: U.S. Department of Transportation- Federal Highway Administration.

ASTM. (2011). Standard specification for retro-reflective sheeting for traffic control. West Conshohocken, PA: ASTM International: Designation: D4956-11a.

Avrenli, K., Benekohal, R., \& Medina, J. (2012). LED roadway lighting volume 1: Background information. Springfield, IL: Illinois Center for Transportation- Bureau of Materials and Physical Research.

Bayam, E., Liebowitz, J., \& Agresti, W. (2005). Older Drivers and Accidents: A Meta Analysis and Data Mining Application on Traffic Accident Data. Expert Systems with Applications, 29(3), 598-629. https://doi.org/10.1016/j.eswa.2005.04.025

Born, A., Viswanathan, A., Thelen, U., Natale, R., Ferreras, A., Gundgaard, J., . . Buchholz, P. (2010). International Vision Requirements for Driver Licensing and Disability Pensions: Using a Milestone Approach in Characterization of Progressive Eye Disease. Clinical Ophthalmology, 4, 1361-1369. https://doi.org/10.2147/OPTH.S15359

Bullough, J. (2012a). Guide for optimizing the effectiveness and efficiency of roadway lighting. Troy, NY: The Lighting Research Center, Rensselar Polytechnic Institute. Retrieved from http://trid.trb.org/view.aspx?id=1144041

Bullough, J. (2012b). New lighting technologies and roadway lighting: An informational brochure. Troy, NY: Lighting Research Center at Rensselaer Polytechnic Institute. Retrieved from

https://www.dot.ny.gov/divisions/engineering/technical-services/trans-r-and-d-repository/C-10-14_RoadwayLighti ng-InformationalBrochure.pdf

Bullough, J., Skinner, N., \& O'Rourke, C. (2008). Evaluation of new reflective materials for overhead highway signage. Troy, NY: Lighting Research Center at Rensselaer Polytechnic Institute. Retrieved from https://www.dot.ny.gov/divisions/engineering/technical-services/trans-r-and-d-repository/C-05-08\%20Reflective\% 20Materials_July\%202008_0.pdf

Burns, L., Jordan, W., \& Scarborough, B. A. (2013). Transforming personal mobility. New York, NY: The Earth Institute, Columbia University.

Daigneault, G., Joly, P., \& Frigon, J. (2002). Executive Functions in the Evaluation of Accident Risk of Older Drivers. Journal of Clinical Experimental Neuropsychology, 24(2), 221-238. https://doi.org/10.1076/jcen.24.2.221.993

Der, G., \& Deary, I. (2006). Age and Sex Differences in Reaction Time in Adulthood: Results from the United Kingdom Health and Lifestyle Survey. Psychology and Aging, 21(1), 62-73. https://doi.org/10.1037/0882-7974.21.1.62

Dewar, R., \& Olson, P. (2007). Human factors in traffic safety (2 ed.). Tucson, AZ: Lawyers and Judges Pulishing Company, Inc.

Dukic, T., \& Broberg, T. (2012). Older Driver's Visual Search Behaviour at Intersections. Transportation Research Part F: Traffic Psychology and Behaviour, 15(4), 462-470. https://doi.org/10.1016/j.trf.2011.10.001

FHWA. (2003). A Pocket guide for improving traffic control and mobility of our older population. Washington, DC: U.S Department of Transportation- Federal Highway Adminstration.

FHWA. (2009). Manual on uniform traffic control devices for sreets and highways (Washington, DC ed.). Washington, DC: U.S. Department of Transportation- Federal Highway Adminstration.

Federal Highway Administration [FHWA]. (2008). New sign retroreflectivity requirements. Washington, DC: The U.S. 
Department of Transportation- Federal Highway Administration. Retrieved from http://www.ltadd.org/pdf/Retroreflectivity-New-Sign-Requirements.pdf

Foley, D., Heimovitz, H., Guralnik, J., \& Brock, D. (2002). Driving Life Expectancy of Persons Aged 70 Years and Older in the United States. American Journal of Public Health, 92(8), 1284-1289.

Green, M. (2000). How Long Does It Take to Stop? Methodological Analysis of Driver Perception-Brake Times. Transportation Human Factors, 2(3), 195-216. https://doi.org/10.1207/STHF0203_1

Highway Safety Research and Communications. (2018). Older drivers. Retrieved March 18, 2018, from http://www.iihs.org/iihs/topics/laws/olderdrivers

Holick, A. J., Chrysler, S. T., Park, E. S., \& Carlson, P. J. (2006). Evaluation of the Clearview font for negative contrast traffic signs. College Station, Texas: Texas Transportation Institute.

Houser, A. (2005). Older drivers and automobile safety. (AARP Public Policy Institute) Retrieved February 20, 2012, from http://assets.aarp.org/rgcenter/il/fs51r_drivers.pdf

Lagergren, E. (1987). Traffic sign retroreflectivity measurement using human observers. Olympia, WA: Washington State Department of Transportation.

Lopez, C. (2003). Highway illumination manual. Austin, TX: Texas Department of Transportation- Traffic Operations Division.

Madden, D. (2001). Speed and timing of behavioral processes. In J. Birren, \& K. W. Schaie (Eds.), Handbook of the Psychology of Aging (pp. 288-310). San Diego, CA: Academic Press.

Markoff, J. (2014). Google's next phase in driverless cars: No steering wheel or brake pedals. The New York times. Retrieved from http://www.nytimes.com/2014/05/28/technology/googles-next-phase-in-driverless-cars-no-brakes-or-steering-whee 1.html?_r=0

McKnight, A. (2003). The Freedom of the Open Road: Driving and Older Adults. Generations, 27(2), 25-31.

Medina, J., Avrenli, K., \& Benekohal, R. (2013). Field and software evaluation of illuminance from LED luminaires for roadway application. Washington, DC: Transportation Research Board.

Momeni, H., Russell, E., \& Rys, M. J. (2015). A Study to mitigate Rrural and urbanhigh-speed horizontal curve crashes in Kansas. Topeka, KS: Kansas Department of Transportation.

National Highway Traffic Safety Administration [NHTSA] (2017). 2016 Fatal motor vehicle crashes: Overview. Washington, DC: U.S. Department of Transportation-National Highway Traffic Safety Administration.

Obeidat, M. S., Rys, M. J., \& Rys, A. (2014b). Evaluation of overhead guide sign sheeting materials. Proceedings of the 2014 Industrial and Systems Engineering Research Conference (pp. 1545-1554). Montreal, Canada: Institute of Industrial Engineering.

Obeidat, M., \& Rys, M. (2015). Evaluation of light sources used for overhead guide sign illumination. Manila, Philippines: International Foundation for Production Research (IFPR).

Obeidat, M., \& Rys, M. (2017). Comparing roadway lighting systems performance at rural and urban intersections. Proceedings of the 2017 Industrial and Systems Engineering Conference (pp. 97-102). Pittsburgh, PA: Institute of Industrial and Systems Engineers.

Obeidat, M., Rys, M., Russell, E., \& Gund, A. (2014a). Determining Cost-effective Policy for Visibility of Overhead Guide Signs on Highways. Transportation Research Forum, 53(2), 45-58.

Obeidat, M., Rys, M., Rys, A., \& Du, J. (2016). Evaluation of Overhead Guide Sign Sheeting Materials to Increase Visibility and Safety for Drivers. Applied Ergonomics, 56, 136-143. https://doi.org/10.1016/j.apergo.2016.03.016

Owsley, C., \& McGwin, G. (2010). Vision and Driving. Vision Research, 50(23), 2348-2361. 1 https://doi.org/10.1016/j.visres.2010.05.021

Phillips, L., Rousseau, G., \& Schwartzberg, J. (2006). Road users can grow old gracefully-with some help. Washington, DC: U.S. Department of Transportation- Federal Highway Administration.

Steinkuller, P. (2010). Legal Vision Requirements for Drivers in the United States. American Medical Association Journal of Ethics, 12(12), 938-940.

Talbot, A., Bruce, I., Cunningham, C., Coen, R., Lawlor, B., Coakley, D., . . O’neill, D. (2005). Driving Cessation in Patients Attending a Memory Clinic. Age and Aging, 34(4), 363-368. https://doi.org/10.1093/ageing/afi090 
U.S. Census Bureau, P. D. (2012). U.S. census bureau projections show a slower growing, older, more diverse nation a half century from now. Retrieved June 18, 2013, from http://www.census.gov/newsroom/releases/archives/population/cb12-243.html

Warshawsky-Livne, L., \& Shinar, D. (2002). Effects of Uncertainty, Transmission Type, Driver Age and Gender on Brake Reaction and Movement Time. Journal of Safety Research, 33(1), 117-128.

https://doi.org/10.1016/S0022-4375(02)00006-3

Zhang, J., Lindsay, J., Clarke, K., Robbins, G., \& Mao, Y. (2000). Factors Affecting the Severity of Motor Vehicle Traffic Crashes Involving Elderly Drivers in Ontario. Accident Analysis \& Prevention, 32(1), 117-125. https://doi.org/10.1016/S0001-4575(99)00039-1

\section{Copyrights}

Copyright for this article is retained by the author(s), with first publication rights granted to the journal.

This is an open-access article distributed under the terms and conditions of the Creative Commons Attribution license (http://creativecommons.org/licenses/by/4.0/). 